\title{
Do the quadriceps and hamstring muscles have an effect on patella stability in trochlear dysplasia?
}

\author{
Ahmed Saad ${ }^{1 A, C, E, F}$, Aamer lqba|2A,C,E,F, Uzo Ehiogu ${ }^{3 A, D, E}$, Steven James ${ }^{2 A, C, D, E, F}$, Rajesh Botchu ${ }^{2 A, C, E, F}$ \\ 'Department of Orthopedics, Royal Orthopaedic Hospital, Birmingham, UK \\ ${ }^{2}$ Department of Musculoskeletal Imaging, Royal Orthopaedic Hospital, Birmingham, UK \\ 3Department of Physiotherapy, Royal Orthopaedic Hospital, Birmingham, UK
}

\section{Abstract}

Introduction: Trochlear dysplasia (TD) is a condition that is characterized by the presence of either a flat or convex trochlear, which impedes the stability of the patellofemoral joint (PFJ). The PFJ function is dependent on many different structures that surround the knee joint. The aim of this study was to analyse all the muscle components around the PFJ and identify whether gross muscle imbalance could contribute to the stability of the patella in TD.

Material and methods: The average cross-sectional area (CSA) and cross-sectional area ratio (CSAR) of each muscle of the thigh region in subtypes of TD was evaluated and compared to normal knee joints. Ninety-eight patients (196 knees in total) were included in the study.

Results: Of the 196 knee joints that were reviewed, 10 cases were found to be normal. In total, 186 cases were positive for TD. The majority consisted of type C. The hamstring muscles showed variable results. The vastus medialis muscle was larger in comparison to the vastus lateralis muscle over all the different TD subtypes; however, no statistical significance was identified. There was a marked statistical significance between the quadriceps and hamstring muscles, especially when comparing this to the normal knees within our cohort.

Conclusions: This study revealed no significant difference in the effect of the thigh muscle CSA on the stability of the $\mathrm{PFJ}$ in TD. Further research is required to establish the roles of the different muscles around PFJ in the prevention of TD dislocation.

Key word: quadriceps, hamstrings, trochlear dysplasia, medial patellofemoral ligament, lateral patellar dislocation, physiotherapy.

\section{Introduction}

Trochlear dysplasia (TD) is characterized by modification in the shape of the femoral trochlear $[1,2]$ and is most prevalent in female adolescents and young adults. The shape of a normal femoral trochlear is concave, allowing the patellar to sit in its usual position throughout the range of movement of the knee joint [1]. In TD, the trochlear is either flat or convex (in severe conditions), hindering the stability of the patellofemoral joint (PFJ). TD can be underdiagnosed in up to $73 \%$ of cases because the patella tends to spontaneously relocate [3]. Therefore, it is vital to ensure early appropriate diagnosis and to allow management of this condition to be instigated.

The PFJ function is supported by a number of structures that surround the knee joint. Studies regarding the impact and contribution of these structures on patellofemoral stability are sparse in the literature [4]. What prevents the patella from dislocating depends on various static and dynamic structures. The soft tissue provides passive stability, most importantly the medial ligaments (medial patellofemoral ligament) [5,6]. The dynamic sta- 


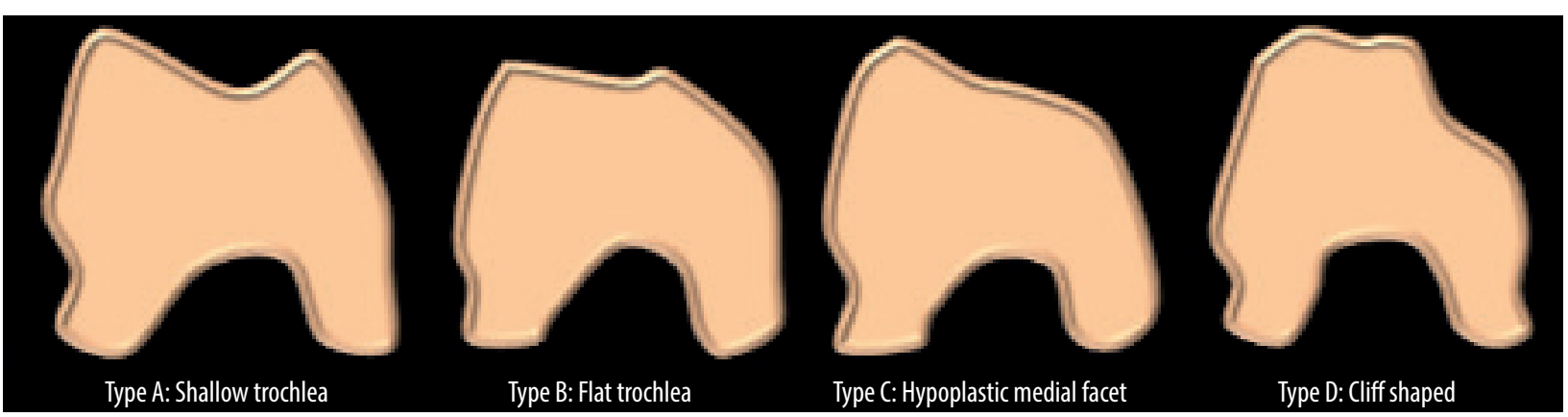

Figure 1. Diagrammatic animation of Dejour trochlear dysplasia

bility depends on the anatomical dimensions of the trochlear groove, the normal valgus position of the knee joint (normal limb alignment), and the quadriceps muscles namely, the vastus medialis [7].

In most cases of TD, the patella dislocates laterally. This is thought to be due to the lateral pulling forces initiated by the lateral quadriceps and patellar tendons [8-10]. The vastus medialis muscle has been found to play an essential role in opposing these forces to provide stability of the PFJ $[11,12]$.

The first-line therapy of managing TD is physical therapy with a combination of proprioceptive exercises, and it is widely accepted that patients should undergo physiotherapy targeting the vastus medialis focusing on muscle strengthening [13-17]. This theory, however, has been questioned because other factors around the knee joint have been found to contribute to the patellar instability $[18,19]$.

The aim of this study was to analyse all the muscle components around the PFJ joint and identify whether gross muscle imbalance could contribute to the stability of the patella in TD.

\section{Material and methods}

We performed a retrospective search of our department's radiology system to identify all patients referred from the knee orthopaedic clinic with suspected trochlear dysplasia over the past 5 years. Within our cohort, all patients underwent cross-sectional imaging computed tomography rotational profiles.

We used Dejour et al. classification to describe the different subtypes of TD obtained in our study [20] (Figure 1).

- Type A is characterized by the presence of a shallow trochlea with a prominent 'crossing sign'.

- Type B is distinguished by the presence of a flat trochlear with a supratrochlear spur (on axial CT images) and a 'crossing sign'.

- Type $\mathrm{C}$ is characterised by a crossing sign and a double contour sign instead of a trochlear spur.

- Type D is typified by the presence of all 3 signs with a sharp convex "cliff" separating the medial and lateral facets on axial CT images.
We calculated the average cross-sectional area ratio (CSAR) of each muscle of the thigh region; the vastus medialis (VM), vastus lateralis (VL), rectus femoris (RF), biceps femoris (BF), semimembranosus and semitendinosus (as one group), the sartorius, and the gracilis. We also evaluated the cross-sectional area (CSA) of each muscle in the specific subtypes of TD and compared this to our normal knee joints within our cohort.

The inclusion criteria included patients with TD or a normal knee joint and no history of previous surgery or existing joint pathologies. Using the 'cranial' most slices of CT axial images of the knee joints during extension and in a resting position, we utilized the most proximal measurement (calculated approximately $5 \mathrm{~cm}$ proximal to the superior pole of the patella) as a standard to evaluate the CSA of the muscles of the mid-thigh region (Figures 2 and 3 ).

Initially, we compared the CSAR of the quadriceps muscle group against the hamstrings and the medial quadriceps (VM) against the lateral quadriceps (VL), and calculated the $p$-values using a used a 1-sample $t$-test to calculate the statistical significance of group differences.

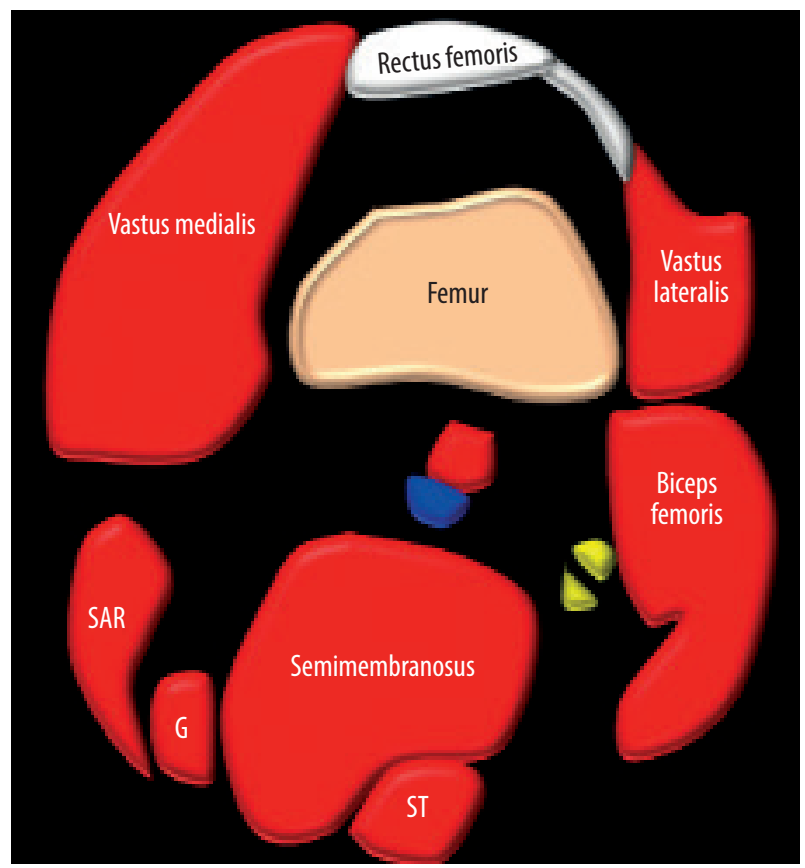

Figure 2. Diagrammatic animation of the axial of the distal thigh. $G$ - gracilis, ST - semitendinosus, SAR - sartorius 

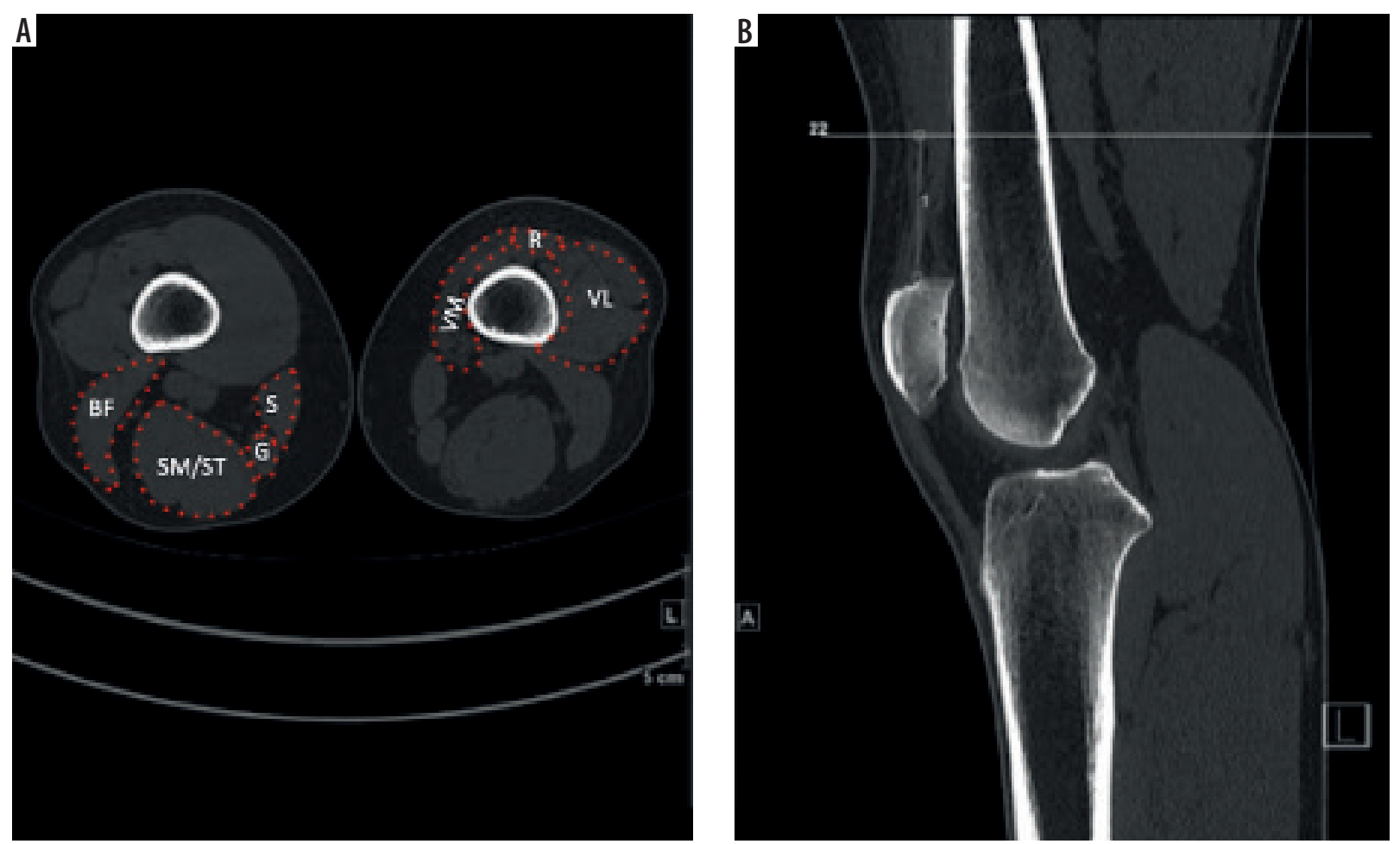

Figure 3. Axial CT (A) and sagittal CT (B) showing the level of measurement of the cross-sectional area of muscles. VM - vastus medialis, $\mathrm{VL}$ - vastus lateralis, $\mathrm{R}$ - rectus femoris, SM/ST - semimembranosus/semitendinosus, BF - biceps femoris, $\mathrm{S}$ - sartorius, $\mathrm{G}$ - gracilis

All images were reviewed by 1 consultant musculoskeletal radiologist and 1 senior radiology trainee within our department. It is important to note that there is no known standardized measurement of muscle surface area, and therefore these isolated results are deemed insignificant. We defined the level of significance as $p<0.05$ in our study.

\section{Results}

We identified 109 consecutive cases in our database, of which 98 patients (196 knees in total) fulfilled the inclusion criteria. Ten cases (20 knees in total) were excluded. The mean age of our patients was 25 years (11-50 years). There was a female-to-male predominance of 67 to 31 (ratio of $2.2: 1$ ).
Of the 196 knee joints that were reviewed, 10 cases were found to be normal. 186 cases were positive for TD. The majority consisted of the Type $C$ variant, equating to $48.9 \%(n=91)$, followed by Type B TD with $25.2 \%$ $(n=47)$. Type A TD was found in $20.4 \%(n=38)$, and type D TD was identified in only $5.4 \%(n=10)$ of all cases.

We found that the Type B variant of TD had the largest CSA measurement of the vastus medialis $\left(1618.5 \mathrm{~mm}^{2}\right)$ muscle with an overall average of $1451.93 \mathrm{~mm}^{2}$ over all subtypes. Type A TD showed the largest surface area measurement over the vastus lateralis $\left(764 \mathrm{~mm}^{2}\right)$ and rectus femoris muscle $\left(273.3 \mathrm{~mm}^{2}\right)$.

The hamstring muscles showed variable results, with distinctly increased CSA observed over semitendinosus and semimembranosus throughout the TD subtypes (average 1055.60). The rectus femoris was hypertrophied over all TD subtypes except type D (average $208 \mathrm{~mm}^{2}$ )

Table 1. The cross-sectional area ( $\mathrm{mm} 2)$ of the muscles of the mid-thigh region over the different subtypes of trochlear dysplasia and normal knee joints in our cohort

\begin{tabular}{|l|c|c|c|c|c|c|c|}
\hline \multirow{2}{*}{$\begin{array}{l}\text { Type } \\
\text { of knee } \\
\text { joint }\end{array}$} & Vastus medialis & Vastus lateralis & Rectus femoris & Biceps femoris & $\begin{array}{c}\text { Semimembranosus } \\
\text { and semitendinosus }\end{array}$ & Gracilis & Sartorius \\
\cline { 2 - 9 }$y$ & & & & & 825.4 & 76.8 & 298.9 \\
\hline A & 1588.7 & 764 & 273.3 & 675.8 & 1104.9 & 75.1 & 331.4 \\
\hline C & 1618.5 & 753.8 & 252.2 & 705.7 & 1106.18 & 67 & 285.5 \\
\hline D & 1440.8 & 712.4 & 262.4 & 702 & 1195.5 & 68.2 & 259.1 \\
\hline Normal & 1266.4 & 638.5 & 208 & 613.9 & 988.6 & 72.2 & 284.7 \\
\hline
\end{tabular}


Table 2. Table showing the cross-sectional area $\left(\mathrm{mm}^{2}\right)$ of the muscles of the thigh of all trochlear dysplasia and normal cases in our cohort

\begin{tabular}{|c|c|c|c|c|c|c|c|}
\hline \multirow{2}{*}{$\begin{array}{l}\text { Type of knee } \\
\text { joint }\end{array}$} & \multicolumn{7}{|c|}{ Surface area of muscles $\left(\mathrm{mm}^{2}\right)$ with $p$-value } \\
\hline & $\begin{array}{l}\text { Vastus } \\
\text { medialis }\end{array}$ & $\begin{array}{l}\text { Vastus } \\
\text { lateralis }\end{array}$ & $\begin{array}{l}\text { Rectus } \\
\text { femoris }\end{array}$ & $\begin{array}{l}\text { Biceps } \\
\text { femoris }\end{array}$ & $\begin{array}{l}\text { Semimembranosus and } \\
\text { semitendinosus }\end{array}$ & Gracilis & Sartorius \\
\hline $\begin{array}{l}\text { Trochlear dysplasia } \\
\text { (all subtypes) }\end{array}$ & 1451.93 & 731.06 & 243.43 & 648.67 & 1055.60 & 65.88 & 282.52 \\
\hline Normal knee & 1252.6 & 562.7 & 239 & 643.6 & 988.6 & 72.2 & 284.7 \\
\hline
\end{tabular}

(Tables 1 and 2). It was clear that the vastus medialis muscle was larger in comparison to the vastus lateralis muscle over all the different TD subtypes and the normal knee joints, with an average ratio of 2.32 to 1 . However, there was no statistical significance between the two muscles, with a calculated $p$-value of 0.313 .

There was also a ratio of $1.16: 1$ between the quadriceps and hamstring muscles, and when comparing this to the normal knees within our cohort, the results showed statistical significance $(p=0.014)$ (Tables 3 and 4; Figures 4 and 5).

\section{Discussion}

Trochlear dysplasia is a known condition exemplified by the presence of a shallow and incongruent connection be-

Table 3. Cross-sectional area ratio between the different muscle groups within our cohort

\begin{tabular}{|l|c|c|c|}
\hline \multirow{2}{*}{$\begin{array}{l}\text { Type } \\
\text { of trochlear }\end{array}$} & \multicolumn{3}{|c|}{ Muscle ratio } \\
\cline { 2 - 4 } & $\begin{array}{c}\text { Vastus medialis/ } \\
\text { Vastus lateralis }\end{array}$ & $\begin{array}{c}\text { Quadriceps/ } \\
\text { Hamstrings }\end{array}$ & $\begin{array}{c}\text { Lateral hamstring/ } \\
\text { Medial hamstring }\end{array}$ \\
\hline $\mathrm{A}$ & 2.26 & 1.19 & 0.47 \\
\hline $\mathrm{B}$ & 2.25 & 1.21 & 0.48 \\
\hline $\mathrm{C}$ & 2.30 & 1.17 & 0.49 \\
\hline $\mathrm{D}$ & 2.45 & 1.08 & 0.43 \\
\hline Normal & 2.52 & 1.47 & 0.65 \\
\hline
\end{tabular}

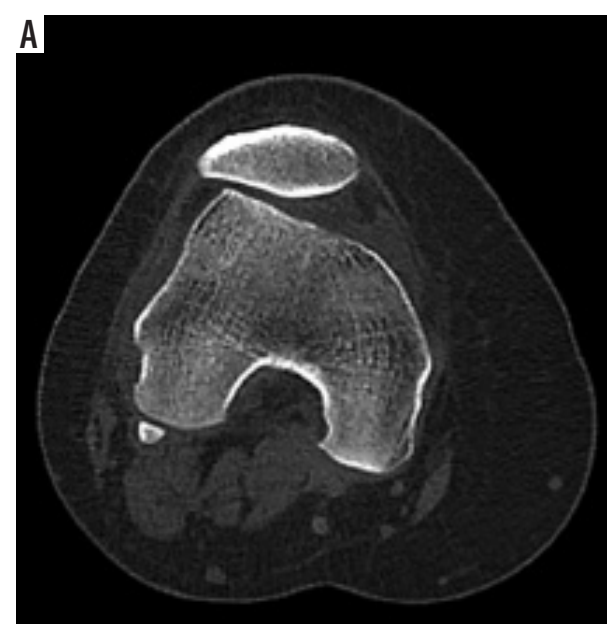

tween the patella and trochlear, which leads to recurrent PFJ dislocation [21].

The stability of this joint in a healthy knee depends on different static and dynamic soft tissue structures. Of them, the most important structure is the medial patellofemoral ligament (MPFL), contributing to approximately $60 \%$ of the force that opposes lateral displacement of the patella. It acts by providing a restraining force that helps reduce the degree of lateral translation [22]. Along with the MPFL, laterally, the stabilizers are made up of the lateral patellofemoral ligament (LPFL), joint capsule, iliotibial band (ITB), and lateral retinaculum [23-25]. The other important structures include the muscles of the thigh, which have also been shown to provide stability, especially during loading and dynamic movements [26]. The kinematic forces that are supplied by these muscles influence the extent of stabilisation of the PFJ.

Table 4. Average cross-sectional area ratio between the different muscle groups with calculated $p$-value within our cohort

\begin{tabular}{|l|c|c|}
\hline \multirow{2}{*}{ Type of knee joint } & \multicolumn{2}{|c|}{ Muscle ratio (cm) } \\
\cline { 2 - 3 } & $\begin{array}{c}\text { Vastus medialis/ } \\
\text { Vastus lateralis }\end{array}$ & $\begin{array}{c}\text { Quadriceps/ } \\
\text { Hamstrings }\end{array}$ \\
\hline Trochlear dysplasia (all subtypes) & 2.32 & 1.16 \\
\hline Normal knee & 2.52 & 1.47 \\
\hline P-value (<0.05) & 0.313 & 0.014 \\
\hline
\end{tabular}

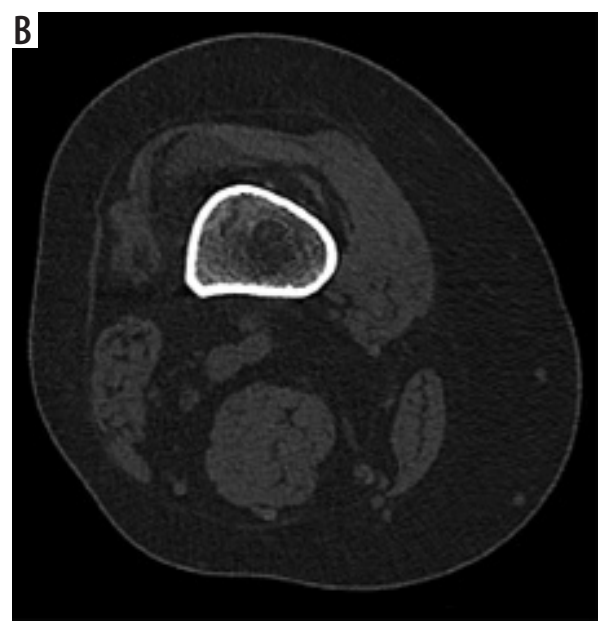

Figure 4. 38-year-old male with type B trochlear dysplasia and moderate atrophy of hamstrings and vastus lateralis 

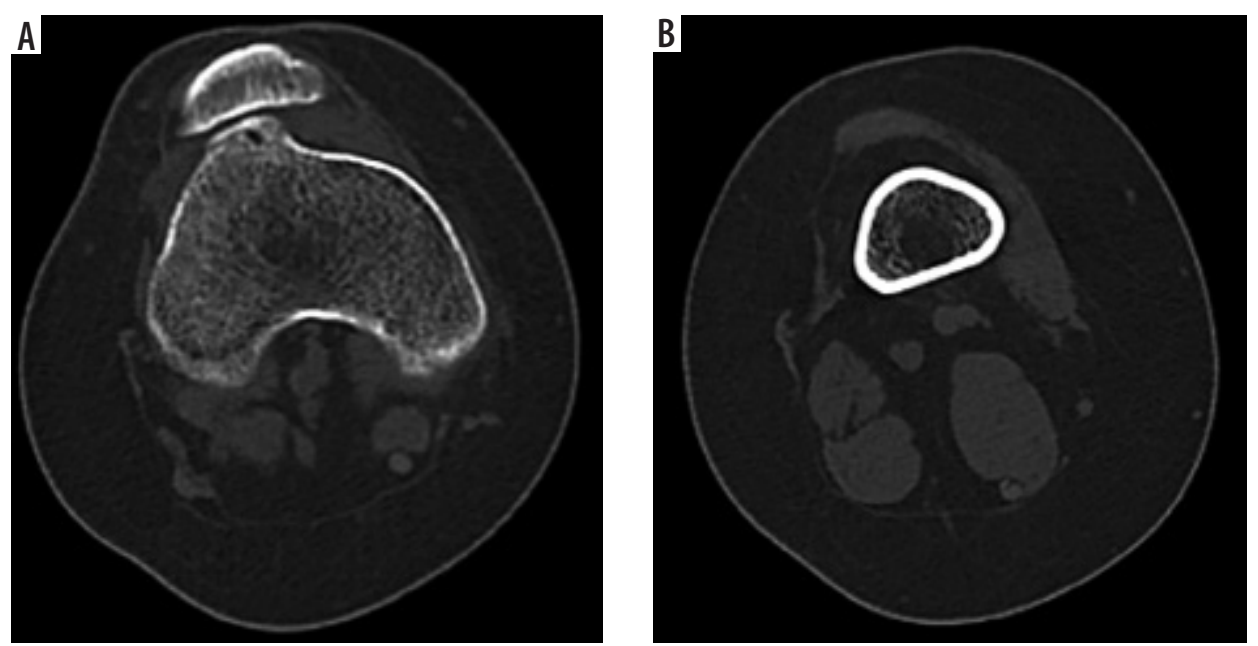

Figure 5. 35-year-old female with type D trochlear dysplasia and marked atrophy of vastus lateralis

Patients with TD suffer from recurrent patellar dislocation; a disabling condition that causes pain, limitation in mobility, and may eventually lead to patellofemoral arthritis. Therefore, diagnoses of TD are essential to ensure early appropriate management is undertaken. Multiple radiographic techniques exist to assess the severity of trochlear dysplasia [27-29]. Both cross-sectional magnetic resonance imaging (MRI) and CT are useful in the diagnosis and evaluation of TD. Moreover, ultrasound imaging is a cost-effective, easily available method that is of particular importance in assessing superficial as well as soft tissue lesions, such as tendinopathies and MPFL tears, which may contribute to patellofemoral instability [30,31].

In various studies, muscle strength (which correlates with force) was found to be directly proportionate to the cross-sectional muscle area (MSCA) [32-35]. When muscle imbalance is present around the patella, patellofemoral diseases may arise. In this study, we concentrated on the distal aspect of the muscles of the thigh, namely the VM and VL and hamstring muscles, with the aim of investigating the size of the different muscles that have been suggested to play a role in the stabilization of the PFJ, and to assess whether muscle imbalance has any significance in guiding the management of TD.

Although the VM muscle is not the most important structure thought to provide stability of the PFJ [4], its importance has been extensively researched and described in the literature $[4,11,12,24]$. In our study, we found that hypertrophy of the VM and VL muscle was evident throughout the different subtypes of TD, with an average CSA ratio of 2.3 to 1 . Whether or not this hypertrophy is due to the natural reaction of the body to counteract the muscular imbalance and prevent the patella displacing laterally is difficult to interpret because this depends on various other static and dynamic structures, as explained previously. Nonetheless, our results correlate with previous studies that have suggested that the restoration of the quadriceps strength and in particular the balance between the VM and VL muscle is considered necessary in offsetting lateral dislocation in TD [36].
Studies regarding the role of the hamstring muscles on the patella and in the stabilization of the PFJ in TD are sparse. The hamstring muscles are composed of the rectus femoris, the semimembranosus and semitendinosus muscles, and possess a biarticular function aiding in hip extension and knee flexion, with medial (by semitendinosus and semimembranosus) and lateral rotation (rectus femoris) of the tibia as the knee is flexed. It is thought that with increased flexion at the knee joint, patients with TD become prone to subluxation and dislocation [37]. This theory stems from the idea that loading of the hamstring muscles causes' tibial posterior translation and external rotation, increasing the lateral translation of the patella [38-41]. Another concept proposed by Escamilla et al. suggests that activation of the hamstring muscles, along with weakness of the quadriceps and lateral patellofemoral malalignment, can increase the lateral pressures and contribute to lateral patellar dislocation [42]. Based on these theories, it is important to target the quadriceps muscles during rehabilitation exercises, and to attempt to minimize the activation of the hamstring muscles to reduce the risk of dislocation. Overall, although our results show hypertrophy of the hamstring muscles throughout the TD subtypes, and according to the mentioned theories, the increased ratio of quadriceps to hamstring muscles may have assisted in the prevention of patellar dislocation [43].

\section{The role of physiotherapy in trochlear dysplasia}

Physiotherapy management is an important intervention for patients who have experienced an episode of instability without evidence of osteochondral injury [44]. Many rehabilitation protocols have been described previously comparing outcomes of non-operative versus operative management in primary acute patella dislocations. These studies have often provided mixed results. Some studies have reported no difference in recurrence rates or subjective functional outcome scores [45-47]. However, other studies have reported significantly lower rates of recur- 
rence and improved outcomes with surgery [48-50]. Physiotherapy for this patient group should take a biopsychosocial approach to the management of this difficult problem and be underpinned by a comprehensive physical examination [51]. The cornerstone of rehabilitation is the restoration of muscular strength and neuromuscular control of the lower quadrant. The programme must ensure optimal neuromuscular rotational control of the joints above and below the knee to prevent dislocation during locomotion [52]. The force-producing capacity of the knee extensors, the hip abductors, and hip extensor musculature is an important target for rehabilitation [53]. This may require a protracted period of intervention to allow adequate recovery of muscle strength for the safe return to physical activities and sport [54]. Additionally, soft tissue flexibility of all structures that could influence patella femoral joint tracking should be assessed and treated to ensure optimal biomechanical balance [55].

\section{Limitations}

It is important to note the limitations in this study, and that the results should be interpreted accordingly. One limitation was the fact that we only used axial CT-rotational images, which helped to evaluate the CSA of the thigh muscles but not to assess the total muscle volume. We also did not measure the amount of fatty infiltration, which may add to the CSA but may not correspond with muscle power. Although we calculated the statistical significance between our cohorts, it is essential to note that we did not have a control group to compare this with, because we imaged only symptomatic patients to minimize the risk of CT radiation. But we did have a group of anatomically normal knees according to Dejour classification to offset this. Finally, it is also important to remark that our study measurements were based on static rather than active knee joints, both of which have different biomechanical influences.

\section{Conclusions}

The main findings of this study revealed no significant difference in the effect of the thigh muscles CSA on the stability of the PFJ in TD. Further research is required to establish the roles of the different muscles around PFJ in the prevention of TD dislocation, to guide the physiotherapy management. It is important to appreciate the roles of the different static and dynamic structures around the PFJ. Targeting the VM muscle independently does not show any significant improvement in prevention of TD dislocation.

\section{Conflict of interest}

The authors report no conflict of interest.

\section{References}

1. Balcarek P, Jung K, Ammon J, et al. Anatomy of lateral patellar instability: trochlear dysplasia and tibial tubercle-trochlear groove distance is more pronounced in women who dislocate the patella. Am J Sports Med 2010; 38: 2320-2327.

2. Diederichs G, Issever AS, Scheffler S. MR imaging of patellar instability: injury patterns and assessment of risk factors. Radiographics 2010; 30: 961-981.

3. Elias DA, White LM, Fithian DC. Acute lateral patellar dislocation at MR imaging: injury patterns of medial patellar soft-tissue restraints and osteochondral injuries of the inferomedial patella. Radiology 2002; 225 736-743.

4. Senavongse W, Amis AA. The effects of articular, retinacular, or muscular deficiencies on patellofemoral joint stabilitiy. J Bone Joint Surg Br 2005; 87: 577-582.

5. Earhart C, Patel DB, White EA, et al. Transient lateral patellar dislocation: review of imaging findings, patellofemoral anatomy, and treatment options. Emerg Radiol 2013; 20: 11-23.

6. Elias DA, White LM. Imaging of patellofemoral disorders. Clin Radiol 2004; 59: 543-557.

7. Zaffagnini S, Grassi A, Zocco G, et al. The patellofemoral joint: from dysplasia to dislocation. EFORT Open Rev 2017; 2: 204-214.

8. White BJ, Sherman OH. Patellofemoral instability. Bull NYU Hosp Jt Dis 2009; 67: 22-29.

9. Fithian DC, Paxton EW, Stone ML, et al. Epidemiology and natural history of acute patellar dislocation. Am J Sports Med 2004; 32: 1114-1121.
10. Fithian DC, Paxton EW, Stone ML, et al. Epidemiology and natural history of acute patellar dislocation. Am J Sports Med 2004; 32: 1114-1121.

11. Pal S, Besier TF, Draper CE, et al. Patellar tilt correlates with vastus lateralis: vastus medialis activation ratio in maltracking patellofemoral pain patients. J Orthop Res 2012; 30: 927-933.

12. Sakai N, Luo ZP, Rand JA, An KN. The influence of weakness in the vastus medialis oblique muscle on the patellofemoral joint: an in vitro biomechanical study. Clin Biomech (Bristol, Avon) 2000; 15: 335-339.

13. Nové-Josserand L, Dejour D. Quadriceps dysplasia and patellar tilt in objective patellar instability. Rev Chir Orthop Reparatrice Appar Mot 1995; 81: 497-504.

14. Tscholl P, Koch P, Fucentese S. Treatment options for patellofemoral instability in sports traumatology. Orthop Rev (Pavia) 2013; 5: e23.

15. Jain NP, Khan N, Fithian DC. A treatment algorithm for primary patellar dislocations. Sports Health 2011; 3: 170-174.

16. Earhart C, Patel DB, White EA, et al. Transient lateral patellar dislocation: review of imaging findings, patellofemoral anatomy, and treatment options. Emerg Radiol 2013; 20: 11-23.

17. White BJ, Sherman OH. Patellofemoral instability. Bull NYU Hosp Jt Dis 2009; 67: 22-29.

18. Smith TO, Bowyer D, Dixon J, et al. Can vastus medialis oblique be preferentially activated? A systematic review of electromyographic studies. Physiother Theory Pract 2009; 25: 69-98. 
19. Farahmand F, Senavongse W, Amis AA. Quantitative study of the quadriceps muscles and trochlear groove geometry related to instability of the patellofemoral joint. J Orthop Res 1998; 16: 136-143.

20. Dejour H, Walch G, Nove-Josserand L, Guier C. Factors of patellar instability: an anatomic radiographic study. Knee Surg Sports Traumatol Arthrosc 1994; 2: 19-26.

21. Reider B, Marshall JL, Koslin B, et al. The anterior aspect of the knee joint. J Bone Joint Surg Am 1981; 63: 351-356.

22. Desio SM, Burks RT, Bachus KN. Soft tissue restraints to lateral patellar translation in the human knee. Am J Sports Med 1998; 26: 59-65.

23. Reider B, Marshall JL, Koslin B, et al. The anterior aspect of the knee joint. J Bone Joint Surg Am 1981; 63: 351-356.

24. Powers CM, Landel R, Perry J. Timing and intensity of vastus muscle activity during functional activities in subjects with and without patellofemoral pain. Phys Ther 1996; 76: 946-955; discussion 956-967.

25. Terry GC, Hughston JC, Norwood LA. The anatomy of the iliopatellar band and iliotibial tract. Am J Sports Med 1986; 14: 39-45.

26. Walsh M, Boling MC, McGrath M, et al. Lower extremity muscle activation and knee flexion during a jump-landing task. J Athl Train 2012; 47: 406-413.

27. Carrillon Y, Abidi H, Dejour D, et al. Patellar instability: assessment on MR images by measuring the lateral trochlear inclination-initial experience. Radiology 2000; 216: 582-585.

28. Stepanovich M, Bomar JD, Pennock AT. Are the current classifications and radiographic measurements for trochlear dysplasia appropriate in the skeletally immature patient? Orthop J Sports Med 2016; 4 : 2325967116669490.

29. Paiva M, Blønd L, Hölmich P, et al. Quality assessment of radiological measurements of trochlear dysplasia; a literature review. Knee Surg Sports Traumatol Arthrosc 2018; 26: 746-755.

30. Corvino A, Sandomenico F, Corvino F, et al. Utility of gel stand-off pad in the detection of Doppler signal on focal nodular lesions of the skin. J Ultrasound 2020; 23: 45-53.

31. Zhang GY, Zheng L, Shi H, et al. Sonography on injury of the medial patellofemoral ligament after acute traumatic lateral patellar dislocation: Injury patterns and correlation analysis with injury of articular cartilage of the inferomedial patella. Injury 2013; 44: 1892-1898.

32. Goldman LH, Tang K, Facchetti L, et al. Role of thigh muscle crosssectional area and strength in progression of knee cartilage degeneration over 48 months - data from the Osteoarthritis Initiative. Osteoarthritis Cartilage 2016; 24: 2082-2091.

33. Jaric S. Muscle strength testing: use of normalisation for body size. Sports Med 2002; 32: 615-631.

34. Segal NA, Findlay C, Wang K, et al. The longitudinal relationship between thigh muscle mass and the development of knee osteoarthritis. Osteoarthritis Cartilage 2012; 29: 1534-1540.

35. Amin S, Baker K, Niu J, et al. Quadriceps strength and the risk of cartilage loss and symptom progression in knee osteoarthritis. Arthritis Rheum 2009; 60: 189-198.

36. Ikai M, Fukunaga T. Calculation of muscle strength per unit crosssectional area of human muscle by means of ultrasonic measurement. Int Z Angew Physiol 1968; 26: 26-32.

37. Lin YF, Lin JJ, Jan MH, et al. Role of the vastus medialis obliquus in repositioning the patella: a dynamic computed tomography study. Am J Sports Med 2008; 36: 741-746.

38. Amin AH, Fahmy MH. Minimal invasive medial patellofemoral ligament reconstruction by hamstring tendon auto-graft. Orthop Muscul Syst 2015; 4: 182 .
39. Kwak SD, Ahmad CS, Gardner TR, et al. Hamstrings and iliotibial band forces affect knee kinematics and contact pattern. J Orthop Res 2000; 18: 101-108.

40. Li G, Rudy TW, Sakane M, et al. The importance of quadriceps and hamstring muscle loading on knee kinematics and in-situ forces in the ACL. J Biomech 1999; 32: 395-400.

41. MacWilliams BA, Wilson DR, DesJardins JD, et al. Hamstrings cocontraction reduces internal rotation, anterior translation, and anterior cruciate ligament load in weight-bearing flexion. J Orthop Res 1999; 17: 817-822.

42. Yoo JD, Papannagari R, Park SE, et al. The effect of anterior cruciate ligament reconstruction on knee joint kinematics under simulated muscle loads. Am J Sports Med 2005; 33: 240-246.

43. Escamilla RF, Fleisig GS, Zheng N, et al. Biomechanics of the knee during closed kinetic chain and open kinetic chain exercises. Med Sci Sports Exerc 1998; 30: 556-569.

44. Elias JJ, Kirkpatrick MS, Saranathan A, et al. Hamstrings loading contributes to lateral patellofemoral malalignment and elevated cartilage pressures: an in vitro study. Clin Biomech (Bristol, Avon) 2011; 26: 841-846.

45. Buchanan G, Torres L, Czarkowski B, Giangarra CE. Current concepts in the treatment of gross patellofemoral instability. Int J Sports Phys Ther 2016; 11: 867-876.

46. Nikku R, Nietosvaara Y, Aalto K, Kallio PE. Operative treatment of primary patellar dislocation does not improve medium-term outcome: a 7-year follow-up report and risk analysis of 127 randomized patients. Acta Orthop 2005; 76: 699-704.

47. Christiansen SE, Jakobsen BW, Lund B, Lind M. Isolated repair of the medial patellofemoral ligament in primary dislocation of the patella: a prospective randomized study. Arthroscopy 2008; 24: 881-887.

48. Petri M, Liodakis E, Hofmeister M, et al. Operative vs conservative treatment of traumatic patellar dislocation: results of a prospective randomized controlled clinical trial. Arch Orthop Trauma Surg 2013; 133 : 209-213.

49. Sillanpaa PJ, Mattila VM, Maenpaa H, et al. Treatment with and without initial stabilizing surgery for primary traumatic patellar dislocation. A prospective randomized study. J Bone Joint Surg Am 2009; 91: 263-273.

50. Bitar AC, Demange MK, D’Elia CO, Camanho GL. Traumatic patellar dislocation: nonoperative treatment compared with MPFL reconstruction using patellar tendon. Am J Sports Med 2012; 40: 114-122.

51. Camanho GL, de Christo Viegas A, Bitar AC, et al. Conservative versus surgical treatment for repair of the medial patellofemoral ligament in acute dislocations of the patella. Arthroscopy 2009; 25: 620-625.

52. Smith TO, Davies L, Chester R, et al. Clinical outcomes of rehabilitation for patients following lateral patellar dislocation: a systematic review. Physiotherapy 2010; 96: 269-281.

53. Fisher B, Nyland J, Brand E, Curtin B. Medial patellofemoral ligament reconstruction for recurrent patellar dislocation: a systematic review including rehabilitation and return-to-sports efficacy. Arthroscopy 2010; 26: $1384-1394$.

54. Fithian DC, Powers CM, Khan N. Rehabilitation of the knee after medial patellofemoral ligament reconstruction. Clin Sports Med 2010; 29: 283-290, ix.

55. Saper MG, Fantozzi P, Bompadre V, et al. Return-to-sport testing after medial patellofemoral ligament reconstruction in adolescent athletes. Orthop J Sports Med 2019; 7: 2325967119828953. 